\title{
The determination of petroleum hydrocarbons in sewer sediment
}

\author{
Ewa Badowska ${ }^{1, *}$, and Anna Bąk $^{1}$ \\ ${ }^{1}$ Lodz University of Technology, Institute of Environmental Engineering and Building Installations, \\ 90-924 Lodz, Al. Politechniki 6, Poland
}

\begin{abstract}
Based on the available standards it is possible to analyze the concentration of petroleum hydrocarbons in sewer sediment. Guidelines included in the standard PN-EN 14039:2008 - Characterization of waste - Determination of hydrocarbon content in the range of C10 to C40 by gas chromatography and in standard PN-EN ISO 16703:2011 - Soil quality - Determination of content of hydrocarbon in the range C10 to C40 by gas chromatography are useful here. The results of analysis concerning elaboration of the methodology of petroleum hydrocarbons determination in sewer sediment based on available literature are presented in the article. According to carried out literature review and the possibilities of available data use, five temperature programs were initially selected. All temperature programs were tested on a standard sample (oil mixture). In the next stage one of prepared method to determine the amount of petroleum hydrocarbons in sewer sediment was applied for sewer sediment come from the combined sewer system. The verification of the sample preparation procedures according to available standards on real sediment revealed the difficulties. Finally, preliminary value of petroleum hydrocarbons concentrations in sewer sediment from the combined sewage system was determined.
\end{abstract}

\section{Introduction}

Petroleum hydrocarbons are one of indicators of rain sewage quality. Unfortunately, despite their negative impact on the environment [1-3] very often the rain sewage is characterized by other indicators. The reason for this may be both procedure and costs of carrying out this type of analyses. The range of determining petroleum hydrocarbons is various, but it is usually in the range between $C_{10}$ and $C_{40}$, which results from the composition of products of crude oil processing [4].

Sewer sediment, which is washed out from sewer system during increased sewer flows, may effect on the quality of rain sewage, and particularly combined sewer. The sudden release of accumulated pollution in sediment increases the pollution load directed to the receiver, and thus increases the negative impact on environment. The amount of sewer sediment in sewer system depends on many factors, for example on hydraulic conditions in the section of the system, the character of the rain phenomenon, or the period of dry

* Corresponding author: ewa.badowska@p.lodz.pl 
weather conditions. Localization of system sections exposed to the accumulation of sediment and sewer sediment qualitative characteristics may contribute to a better, more environmentally-friendly exploitation of sewage system.

\section{Methodology for determination of petroleum hydrocarbons in sewer sediment}

In the performed analysis the methodology for determining the amount of petroleum hydrocarbons in sewer sediment was based on the available standards for determining the amount of petroleum hydrocarbons in waste (Characterization of waste - Determination of hydrocarbon content in the range of $\mathrm{C} 10$ to $\mathrm{C} 40$ by gas chromatography) [5] and soils (Soil quality - Determination of content of hydrocarbon in the range $\mathrm{C} 10$ to $\mathrm{C} 40$ by gas chromatography) [6]. Quoted standards [5,6], because of the lack of standard directly dedicated to sewer sediment, provided the basis for the process of determining the amount of petroleum hydrocarbons in sewer sediment. Two standards were applied because the range of the analysed compounds, the basic methodology for the preparation of samples and the formula for calculating the final amount of petroleum hydrocarbons in both standards are similar.

Separate stage in the preparation of searching the methodology was determination of chromatographic analysis conditions. In the table below the summary literature review concerning the temperature conditions applied in the determination of petroleum hydrocarbons in sediment, soils and waste are presented.

Table 1. The temperature conditions in the process of determination of petroleum hydrocarbons, by means of gas chromatography, according to literature review.

\begin{tabular}{|c|c|c|c|c|c|c|c|c|}
\hline $\begin{array}{c}\text { Parameter/ } \\
\text { Reference }\end{array}$ & $1[7]$ & $2[8]$ & $3[9]$ & $4[10]$ & $5[11]$ & $6[12]$ & $7[6]$ & $8[5]$ \\
\hline $\begin{array}{c}\text { Detector } \\
\text { temperatue } \\
{\left[{ }^{\circ} \mathrm{C}\right]}\end{array}$ & & 300 & 300 & 315 & 310 & 340 & 360 & 360 \\
\hline $\begin{array}{c}\text { Initial } \\
\text { temperature } \\
{\left[{ }^{\circ} \mathrm{C}\right]}\end{array}$ & 60 & 40 & 35 & 60 & 50 & 40 & 80 & 80 \\
\hline $\begin{array}{c}\text { Linear } \\
\text { temperature } \\
\text { increase } \\
{\left[{ }^{\circ} \mathrm{C} / \mathrm{min}\right]}\end{array}$ & 3 & 4 & 14 & 1 & 2 & 0.5 & 1 & 1 \\
\hline $\begin{array}{c}\text { Final } \\
\text { temperature } \\
{\left[{ }^{\circ} \mathrm{C}\right]}\end{array}$ & 320 & 300 & 320 & 290 & 310 & 340 & 360 & $\begin{array}{l}300 / \\
360\end{array}$ \\
\hline Time $[\mathrm{min}]$ & 20 & 10 & 10 & 7 & 18.5 & 0.5 & 15 & $10 / 15$ \\
\hline $\begin{array}{c}\text { Injection } \\
\text { temperature } \\
{\left[{ }^{\circ} \mathrm{C}\right]}\end{array}$ & & 250 & 250 & 285 & 300 & 350 & & \\
\hline Application & $\begin{array}{l}\text { sewer } \\
\text { sedi- } \\
\text { ment }\end{array}$ & $\begin{array}{l}\text { bottom } \\
\text { sedi- } \\
\text { ment }\end{array}$ & $\begin{array}{l}\mathrm{C}_{12}-\mathrm{C}_{40} \\
\text { water } \\
\text { and soil }\end{array}$ & $\begin{array}{c}\mathrm{C}_{9}-\mathrm{C}_{40} \\
\text { water, } \\
\text { soil, } \\
\text { sedi- } \\
\text { ment }\end{array}$ & $\begin{array}{l}\text { soil and } \\
\text { sedi- } \\
\text { ment }\end{array}$ & $\begin{array}{l}\text { water, } \\
\text { soil, } \\
\text { sedi- } \\
\text { ment }\end{array}$ & soil & waste \\
\hline
\end{tabular}

After a preliminary analysis of the literature review five temperature programs [7-12], possible to analyse, were extracted. All analyses using the Bruker 450 gas 
chromatograph equipped with a flame ionization detector (FID) and column Varian Capillary Column Select TM Mineral Oil LVI were conducted. The capillary column $15 \mathrm{~m}$ in length and $0.32 \mathrm{~mm}$ in diameter was used. There were used: nitrogen as carrier gas, air and hydrogen as auxiliary gases.

Each of the selected temperature program was modified several times to obtain a chromatogram, similar in shape to presented in standard $[5,6]$. While changes in temperature programs were tested, the samples prepared using the standard containing a mixture of oils (RIVM-NMi-001), in which the amount of the concentration of petroleum hydrocarbons was in the range from 0.5 to $12.0 \mathrm{mg} / \mathrm{ml}$, were applied. Achieving chromatogram for standard samples the in shape similar to that presented in standard (Fig. 1) confirms the appropriate conditions of chromatographic analysis and allows using analysed method to determine the amount of petroleum hydrocarbons in real samples.

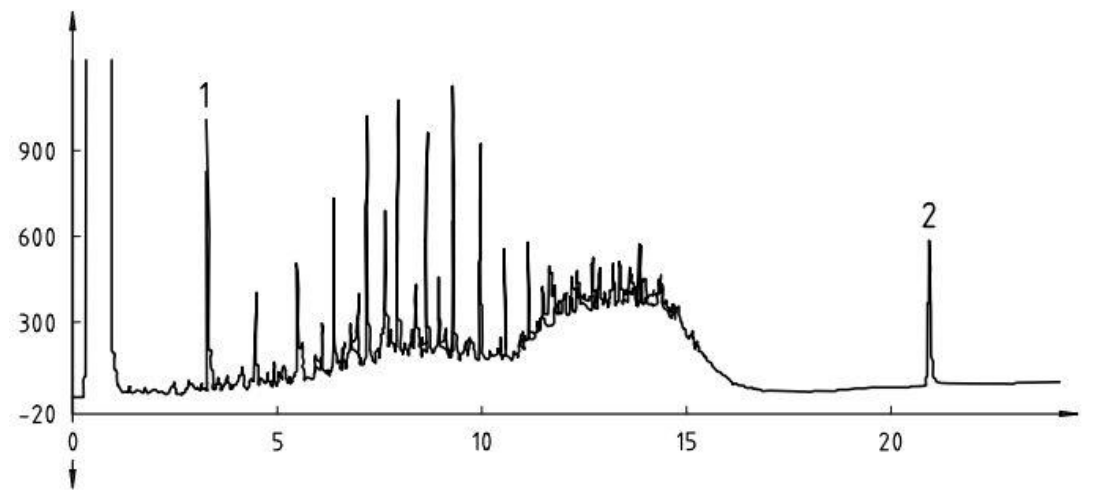

Fig. 1. Gas chromatogram of the calibration mixture consisting of equal parts of diesel fuel and lubricanting oil $[5,6]$.

\section{Results}

The results obtained during the research, after every change in temperature program, were analyzed and on this base further modifications in individual temperature program were determined. In case it is ascertained that changes carried out, to certain time (change of temperature, time) do not give the desired result, for example, there is inadequate separation of peaks, resigned from further changes were not made. Finally, temperature program, which was used to analyse the quality of sewer sediment from the combined sewer system, was achieved. In this way the procedure of the preparation and analysis on real samples was verified.

\subsection{The selected temperature program}

Temperature program that best fulfilled set conditions was program 2 [8] with the initial settings $\left(40^{\circ} \mathrm{C}\right.$ for $4 \mathrm{~min} / 20^{\circ} \mathrm{C} / \mathrm{min}$ to $300^{\circ} \mathrm{C} / 300^{\circ} \mathrm{C}$ for $\left.10 \mathrm{~min}\right)$. On the figure below (Fig. 2) the chromatogram of the sample at a concentration of $3.0,5.0$, and $8.0 \mathrm{mg} / \mathrm{ml}$ for the initial setup of method 2 [8] is presented. 


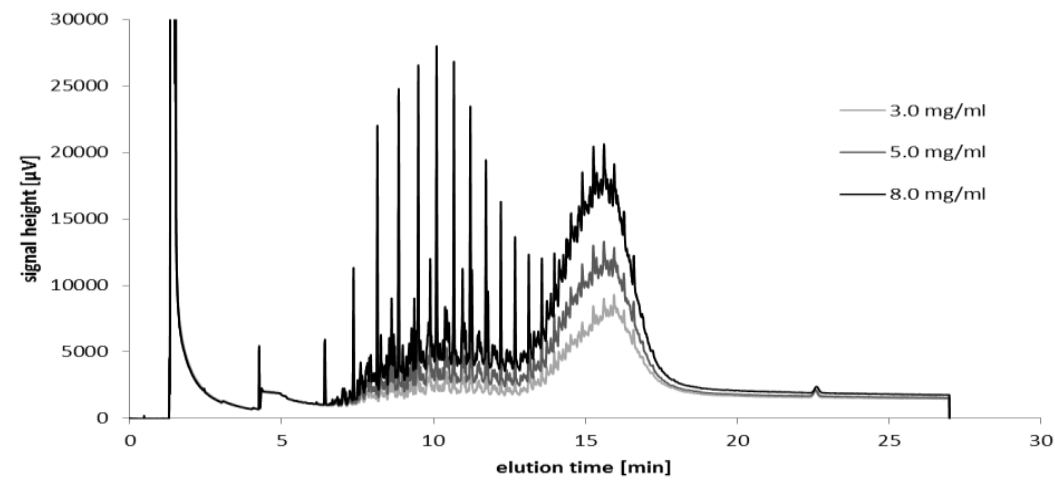

Fig. 2. Gas chromatograms of standard (mixture of mineral oil) of $3.0,5.0$ and $8.0 \mathrm{mg} / \mathrm{ml}$ concentration analyzed using method 2 .

In the chromatograms presented above the peaks limiting the range of analysis (n-decane and n-tetracontane) are clearly visible. In addition, the left side of the graph is characterized by well-separated single peaks, and the right has a characteristic hump. Method 2 [8] worked well for both low and high concentrations of standard sample. However, attention was paid to retention time of n-decane, which amounted more than 6 minutes. Too long retention time unnecessarily lengthens the entire analysis, which affects the quantity of used gas. In order to optimize the process the initial temperature of $40^{\circ} \mathrm{C}$ was changed to $60^{\circ} \mathrm{C}$ and $80^{\circ} \mathrm{C}$. Increasing the initial temperature achieved the expected effect of shortening the retention time of $n$-decane. It is also noted that at increased initial temperature the baseline of individual peaks was decreased. Total analysis time could be reduced due to the shift of peaks of n-tetracontane. Better results were obtained for an initial temperature of $80^{\circ} \mathrm{C}$. Figure below shows the chromatogram for a saple of $1 \mathrm{mg} / \mathrm{ml}$ concentration obtained after changing the initial temperature to $80^{\circ} \mathrm{C}$.

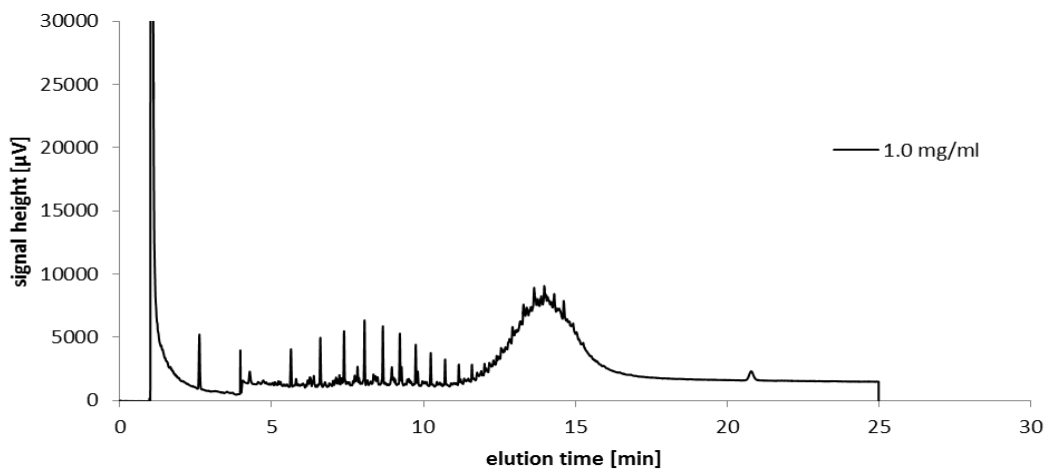

Fig. 3. Gas chromatogram of standard sample of $1 \mathrm{mg} / \mathrm{ml}$ concentration obtained after changing initial temperature to $80^{\circ} \mathrm{C}$.

In the next stage, it was decided to make changes that would result in a better separation of the individual peaks. For this purpose, increase linear of temperature from $20^{\circ} \mathrm{C} / \mathrm{min}$ to $10^{\circ} \mathrm{C} / \mathrm{min}$ was reduced. Unfortunately, this change was associated with prolongation of the total analysis time. In the figure below, the effects of rate changes of temperature increase are shown. 


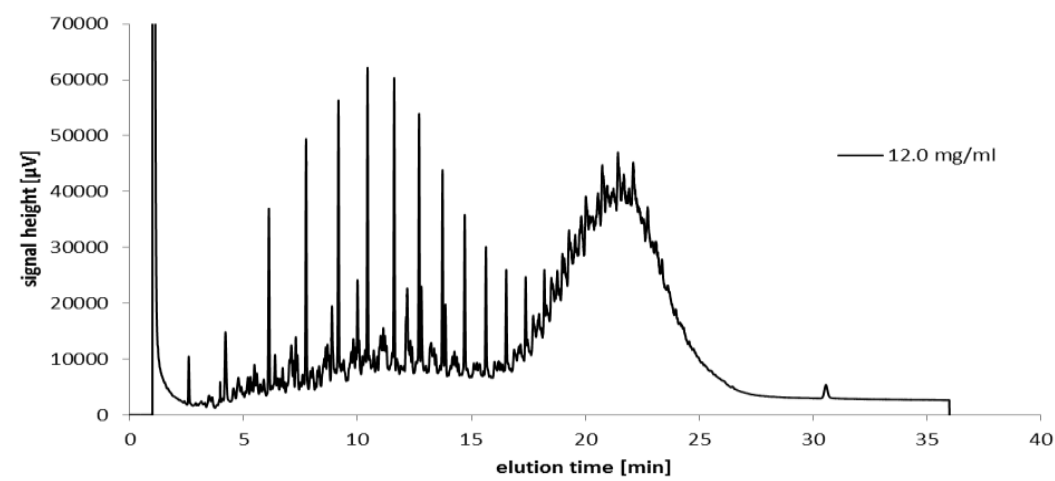

Fig. 4. The gas chromatogram of sample standard solution of $12 \mathrm{mg} / \mathrm{ml}$ concentration obtained after changing temperature increase to $10^{\circ} \mathrm{C} / \mathrm{min}$.

It was decided, on the basis of figure shape (Fig. 4) that the gas chromatogram meets the basic conditions classifying the temperature program as possible to use in determining the concentration of petroleum hydrocarbons. Clearly visible peaks n-decane and n-tetracontane (compounds limiting the scope of the analysis), occuring well-separated individual peaks and occuring hump point it out.

In the next stage, the reproducibility of results through 5 times solution injection of $4 \mathrm{mg} / \mathrm{ml}$ concentrations was verified. On the basis of figures, the average area of the peaks of the analyzed solution and the corresponding its standard deviation, which amounted to 2.7\%, was calculated (PN-EN 14039: 2008 and PN-EN ISO 16703:2011 standards allow standard deviation max 5\%).

Determined and verified the temperature program was used to plot calibration curves using a hydrocarbon solvent, n-hexane and n-heptane. It was decided to use the two hydrocarbon solvents, in order to verify later their usefulness in determining the amount of petroleum hydrocarbons in sewer sediment in real samples. The calibration curves using the following standard solution of $0.2,0.4,0.6,0.8,1.0,4.0$ and $8.0 \mathrm{mg} / \mathrm{ml}$ concentrations were made. Respectively calibration curve equation for n-hexane (1) and n-heptane (2) for analyzed concentrations were obtained. The determination coefficient in both cases was approximately $\mathrm{R}^{2}=0.99$.

$$
\begin{aligned}
& y=26.714 x+1322.5 \\
& y=29.772 x+628.17
\end{aligned}
$$

\subsection{Sample preparation}

Preparation of real samples for chromatographic analysis is an important step which has great impact on the final result. Correct sampling is the first step in the determination of petroleum hydrocarbons in sewer sediment. The samples of sewer sediment from the selected location (combined sewer) were as far as possible (the amount of sediment in the channel) taken from the upper layer. In some cases, because of the precipitation frequency, the amount of sewer sediment in the channel was so small that the collection of the top layer was not possible. A small amount of sewer sediment in the channel also influenced in the next stage the procedure for sample preparation (homogenization). In cases, where there was little amount of sewer sediment before homogenization process, it was necessary to remove large solids (stone, glass) from a sample. Then, the sample after addition of the appropriate reagents (according to standard) and shaking was transferred to a separatory funnel and washed to remove the acetone. Shaking process provides sedimentation of solids 
and allows the collection of supernatant which is used in the later stages of the analysis. Finally, prepared in this way samples are treated on Florisil columns (diatomaceous substance) and ready for chromatographic analysis. The methodology of sample preparation for the analysis of the amount of petroleum hydrocarbons in sewer sediment turned out to be a difficult process. The quality of sewer sediment sample (its consistency, quantity) has the biggest impact.

\subsection{The amount of petroleum hydrocarbons in sewer sediment from combined sewer system}

The conducted analysis concerning establishing the conditions for determining the amount of petroleum hydrocarbons in sewer sediment were tested on seven sample series coming from combined sewer system of Lodz. The collection point was located just before the combined sewer overflow J-1, which is located in the southern part of the city. The catchment assigned to combined sewer overflow $\mathrm{J}-1$ is the urbanized area where there is a multi-family housing, public buildings and numerous points of service.

The conducted research can be divided into two parts. The first part concerns the analysis carried out in July 2016 year ( 5 collections), while the second contains two series of samples that have been made at the turn of 2016 and 2017. In the first part of the research, except for one case (the first series), from which 3 samples with hexane and 1 with heptane were prepared, two samples using n-hexane and n-heptane as hydrocarbon solvent were prepared. In the second part of the analysis three samples using n-hexane and n-heptane were made. The table below shows the values of amount of petroleum hydrocarbons in the analyzed sewer sediment.

Table 2. The summary results of the contents of petroleum hydrocarbons in sewer sediment.

\begin{tabular}{|c|c|c|c|}
\hline Collection date & Solvent & Average value mg/kg drs & Efficiency $\%$ \\
\hline \multirow{2}{*}{14.07 .2016} & n-hexane & 98.64 & 27.37 \\
\cline { 2 - 4 } & n-heptane & 43.70 & 27.79 \\
\hline \multirow{2}{*}{18.07 .2016} & n-hexane & 87.18 & 21.94 \\
\cline { 2 - 4 } & n-heptane & 74.18 & 22.25 \\
\hline \multirow{2}{*}{21.07 .2016} & n-hexane & 283.84 & 16.17 \\
\cline { 2 - 4 } & n-heptane & 64.85 & 62.27 \\
\hline \multirow{2}{*}{25.07 .2016} & n-hexane & 245.83 & 5.76 \\
\cline { 2 - 4 } & n-heptane & 198.80 & 9.21 \\
\hline \multirow{2}{*}{28.07 .2016} & n-hexane & 91.79 & 19.08 \\
\cline { 2 - 4 } & n-heptane & Rejected sample \\
\hline \multirow{2}{*}{21.12 .2016} & n-hexane & 630.25 & 2.39 \\
\cline { 2 - 4 } & n-heptane & 612.00 & 2.73 \\
\hline \multirow{2}{*}{03.01 .2017} & n-hexane & 395.34 & 5.66 \\
\cline { 2 - 4 } & n-heptane & 426.52 & 5.37 \\
\hline
\end{tabular}

From the summary table it clearly results that in the initial analysis the procedure of sample preparation was inaccurate. This is evidenced by the values shown in the last column of Table 2 . These values relating to the blank values in accordance with the standard $[5,6]$ should not exceed $10 \%$. The first samples which were prepared correctly (a value of 10\% was not exceeded) were sewer sediment samples collected on 25.07.2016. 
This results from the improvement of the process of sample preparation for chromatographic analysis. The samples from next collection (28.07.2016) prepared with $\mathrm{n}$-heptane were rejected, whereas in samples prepared with n-hexane the value $10 \%(19.08)$ were exceeded. The main issue, in this series of samples, determined sediment which for sample with n-heptane not sediment completely, which caused difficulties in later part of analysis leading finally to the rejection of samples. On July 28, 2016, the amount of sewer sediment in the channel was great, but it was not a sewer sediment which accumulated in the channel successively (a small amount of sewer sediment and the wet weather conditions on 25.07.2016). In the other two samples series carried out in the second part of the research, after conducted another corrections in the samples preparation, the values fulfil the requirement of $10 \%[5,6]$. It can therefore be concluded that efficiency of sample preparation for determination of petroleum hydrocarbons in sewer sediment using gas chromatography was achieved. The results obtained, meeting the guidelines (10\%), fall into the range of determination specified in the standards $[5,6]$ amounting between $100-10000 \mathrm{mg} / \mathrm{kg}$ dry matter, therefore, the selected standards could be used in the present case. In the second part of the analysis the sewer sediment quality was significantly better, which greatly simplified the samples preparation (mainly the homogenisation process). Also a higher value of amount of petroleum hydrocarbons in the analyzed sewer sediment up to $630 \mathrm{mg} / \mathrm{kg} \mathrm{dms}$ (n-hexane) and $612 \mathrm{mg} / \mathrm{kg} \mathrm{dms}$ (n-heptane) was received. This amount of petroleum hydrocarbons in the sewer sediment cause disqualification of sewer sediment as a safe and possible for the storing on landfill, where the maximum limit value amounts $500 \mathrm{mg} / \mathrm{kg} \mathrm{dms}$ [14].The figure below shows the gas chromatogram of sewer sediment sample collected on 21.12.2016 prepared using n-hexane as the hydrocarbon solvent.

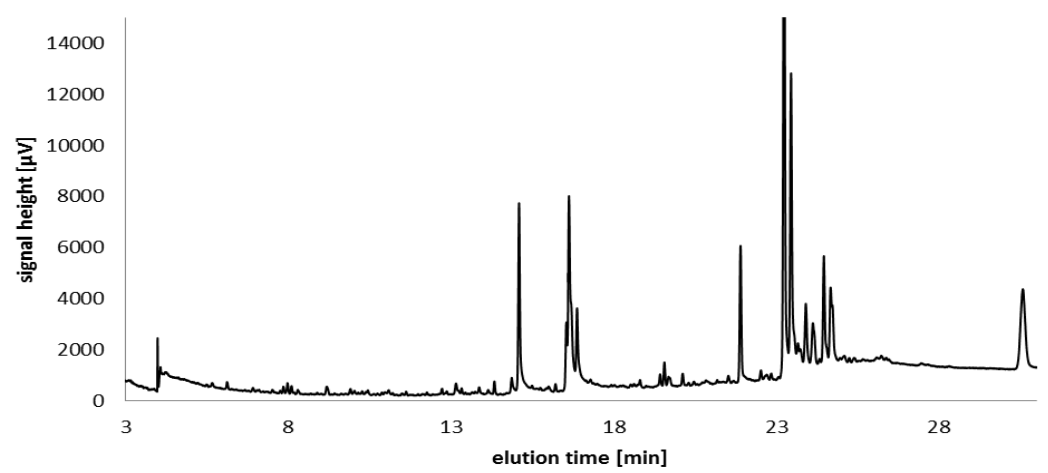

Fig. 5. Gas chromatogram of sewer sediment sample collected on 21.12.2016.

In carried out research also the impact of dry weather conditions period on the value of petroleum hydrocarbons in the sewer sediment was taken into consideration. Unfortunately due to the very short periods of dry weather conditions no connection between accumulation of petroleum hydrocarbons in sewer sediment during dry weather conditions was found. It can only be noted that the sewer sediment characterized by good consistency, which enables conducting the analysis, is formed after longer periods of dry weather conditions.

\section{Conclusions}

1. Using the available standards $[5,6]$ allows the determination of petroleum hydrocarbons in sewer sediment. 
2. The temperature program $\left(80^{\circ} \mathrm{C}\right.$ for $4 \mathrm{~min} / 10^{\circ} \mathrm{C} / \mathrm{min}$ to $300^{\circ} \mathrm{C} / 300^{\circ} \mathrm{C}$ for $10 \mathrm{~min}$.) allowing the analysis of the study compounds using the available equipment was determined.

3. Both n-hexane and n-heptane can be used as hydrocarbon solvents during the determination process of petroleum hydrocarbons in sewer sediment.

4. The quality of the sewer sediment (the consistency) has a significant impact on the preparation of samples for further analysis.

5. Improving the procedure for sample preparation ensured obtaining $10 \%$ efficiency of the determination process.

6. Some parts of the analyzed sewer sediment samples contain more than $500 \mathrm{mg} / \mathrm{kg} \mathrm{dms}$, which prevents their storage [13].

7. The determination of the impact of dry weather conditions on the amount of petroleum hydrocarbons in sewer sediment requires many sample series.

\section{References}

1. S.J. Varjani, Bioresour. Technol., 223, 277 (2017).

2. R.N. Montagnolli, P.R. Matos Lopes, E.D. Bidoia, Arch. Environ. Contam. Toxicol., 68, 342 (2015).

3. ATSDR, Toxicological profile for total petroleum hydrocarbons (TPH), (1999).

4. J. Surygała, Ropa naftowa a środowisko przyrodnicze, (Oficyna Wydawnicza Politechniki Wrocławskiej, 2001).

5. PN-EN 14039:2008, Characterization of waste - Determination of hydrocarbon content in the range of C10 to C40 by gas chromatography, (2008).

6. PN-EN ISO 16703:2011, Soil quality - Determination of content of hydrocarbon in the range C10 to C40 by gas chromatography, (2011).

7. E. Hartmann, W.A. Bischoff, M. Kaupenjohann, Untersuchung von Klärschlamm auf ausgewählte Schadstoffe und ihr Verhalten bei der landwirtschaftlichen Klärschlammverwertung (Berlin, 2004).

8. M. Gąsiorek, Zeszyty Naukowe. Inżynieria Środowiska (Oficyna Wydawnicza Uniwersytetu Zielonogórskiego, 2009).

9. Tennessee State Government, Method for determination of extractable petroleum hydrocarbons by GC/FID.

10. G. Toffoli, Extractable petroleum hydrocarbons methodology, (2010).

11. P. Kurán̆, The Scientific World Journal, 2014, 1 (2014).

12. F. David, K. Jacq, B. Tienpont, High Throughput Mineral Oil Analysis. (Hydrocarbon Oil Index) by GC-FID using the Agilent Low Thermal Mass, (2011).

13. Regulation of the Minister of the Economy on acceptance of waste to store on landfill, Jaw of Laws 2015, pos. 1277, (2015). 